J. Dairy Sci. 98:2205-2214

http://dx.doi.org/10.3168/jds.2014-8857

(C) American Dairy Science Association ${ }^{\circledR}, 2015$.

\title{
Packaging modifications for protecting flavor of extended-shelf-life milk from light
}

\author{
D. S. Johnson, S. E. Duncan, ${ }^{1}$ L. M. Bianchi, H. H. Chang, W. N. Eigel, and S. F. O’Keefe \\ Department of Food Science and Technology, Virginia Polytechnic Institute and State University (Virginia Tech), Blacksburg 24061
}

\begin{abstract}
The effectiveness of titanium dioxide $\left(\mathrm{TiO}_{2}\right)$-loaded high-density polyethylene (HDPE) to reduce lightinduced oxidation of extended-shelf-life milk ( $2 \%$ total fat) was studied. The objective was to determine differences over time in sensory quality, vitamin retention, and oxidative chemistry as a function of packaging and retail light exposure duration. Effectiveness of packaging for protecting milk quality was assessed by sensory evaluation (triangle tests, untrained panel), changes in volatile compounds, thiobarbituric reactive substances (TBARS), and riboflavin concentration. Milk (2\%) was stored in HDPE packages consisting of $\mathrm{TiO}_{2}$ at 3 levels (low: $0.6 \%$; medium: $1.3 \%$; high: $4.3 \%$ ) at $3^{\circ} \mathrm{C}$ for up to $43 \mathrm{~d}$. Light-protected (translucent, foil-wrapped) and light-exposed (translucent) HDPE packages served as controls. The high $\mathrm{TiO}_{2}$-HDPE package provided protection similar to light-protected control package through d 22 of light exposure, with less consistent performance by the medium $\mathrm{TiO}_{2}$ package. The TBARS increased in all treatments during storage. Under the experimental conditions used, a TBARS value of 1.3 $\mathrm{mg} / \mathrm{L}$ could be considered the limiting sensory threshold for differentiating oxidized milk from light-protected milk. Riboflavin concentration decreased $10.5 \%$ in the light-protected control and $28.5 \%$ in the high $\mathrm{TiO}_{2}$ packaged milk past $29 \mathrm{~d}$ of light exposure, but losses were greater than $40 \%$ for all other packages. The high $\mathrm{TiO}_{2}$ package protected riboflavin concentration from degradation and controlled aldehyde concentration throughout the test period.
\end{abstract}

Key words: oxidation, sensory, riboflavin, extendedshelf-life milk

\section{INTRODUCTION}

Milk and milk products are susceptible to lightinduced oxidation reactions, which can negatively af-

Received September 15, 2014

Accepted December 18, 2014.

${ }^{1}$ Corresponding author: duncans@vt.edu fect odor and flavor attributed to increased oxidationderived volatile compound production and leading to reduced shelf-life. Photooxidation of milk occurs under the presence of light (artificial, sunlight) and in both UV and visible light wavelength regions (Webster et al., 2009). This process is of particular concern in milk because it occurs quickly and influences consumer perception of milk flavor (Heer et al., 1995; Chapman, 2002; Chapman et al., 2002; Duncan and Webster, 2010).

Although no direct evidence exists that light-oxidized off-flavors contribute to decreased sales of fluid milk, the relationship of light-oxidized flavor to milk acceptability and emotional response has recently been reported (Walsh et al., 2014). Light-exposed milk (2\% milkfat; $8 \mathrm{~h}$ of light exposure) was rated lower in acceptability, corresponding to "neither like nor dislike," than milk that did not receive light-exposure, which was rated as "like moderately" (Walsh et al., 2014). With continued light exposure (up to $168 \mathrm{~h}$ ), milk acceptability scores decreased to "dislike moderately." The experience of drinking high-quality milk without light-oxidized flavor is characterized by positive emotional terms such as content, good, calm, satisfied, pleased, and happy (Walsh et al., 2014). In contrast, emotional terms that suggested withdrawal and had negative connotations, including disgusted and worried, were frequently selected for the disliked light-exposed milk (Walsh et al., 2014). Such responses illustrate that light exposure during retail storage can be detrimental to milk acceptability and increase negative emotional responses.

Specialty and single-serve milk products are often processed for extended shelf life (ESL), allowing for distribution across greater distances and limited processing schedules of products that have lower turnover or are seasonal products. Longer storage periods increase the risk of light exposure with the subsequent risk of altering milk quality before purchase. Milk is commonly displayed under fluorescent or light-emitting diode (LED) lighting in retail dairy cases in supermarkets, convenience stores, as well as vending machines. Whereas fluorescent lighting is most common in retail dairy cases, LED lighting use in open dairy retail cases is rapidly increasing, from about 15\% in 2010 to almost 
40\% in 2014 (Jack Sjogren, Hillphoenix, Chesterfield, VA, personal communication). Both LED and fluorescent lighting sources deliver light energy in UV and visible wavelength regions that cause excitation of photosensitive molecules, specifically riboflavin (Rb), in milk.

Several molecules in milk are responsive to light, acting as photosensitizers, including $\mathrm{Rb}$, protoporphyrin, hematoporphyin, chlorophyll a and b, and unidentified tetrapyrroles (Webster et al., 2009, 2011; Duncan and Chang, 2012). Photosensitizers initiate oxidation after being activated by light. Photosensitizers are important because they cause the destruction of milk components usually unaffected directly by light (Boff and Min, 2002). Excitation of Rb, the most studied photosensitizer in milk (Sattar et al., 1976; Wold et al., 2005; Webster et al., 2009), occurs when exposed to light at 250, 270, 370, 400, 446, and $570 \mathrm{~nm}$ wavelengths (Kyte, 1995). Some LED lights have visible light spectrums with greatest intensity at the wavelengths of greatest concern. Detrimental retail case lighting effects may be alleviated by selecting appropriate packaging materials to minimize the transmission of light (Duncan and Hannah, 2012).

In the United States, milk is commonly packaged in waxed paperboard, high-density polyethylene (HDPE) or polyethylene terephthalate (PETE). The HDPE transmits 57 to $60 \%$ of light wavelengths between 300 and $700 \mathrm{~nm}$ (van Aardt et al., 2001; Duncan and Hannah, 2012). The packaging material frequently used for single-serve milk products, PETE, transmits up to 75 to $85 \%$ of visible light. Packaging material can have a protective effect on milk quality through blocking or reducing the transmission of certain light wavelengths (Webster et al., 2009). It is important, then, to develop packaging materials that are consumer friendly yet block the most damaging wavelengths to milk quality.

One possible packaging innovation that has shown usefulness in protecting against photooxidation is titanium dioxide $\left(\mathrm{TiO}_{2}\right)$. Since its commercial production in the early 20th century, $\mathrm{TiO}_{2}$ has been widely used as a leading white pigment in paints, toothpaste, and packaging. Titanium dioxide is a photo-responsive material and its importance is steadily increasing in the polymer and plastic industry (DuPont, 2007). Due to its ability to scatter light and absorb UV light energy, $\mathrm{TiO}_{2}$ has been added at different concentrations to HDPE and PETE (Robertson, 2006). Moysssiadi et al. (2004) showed that a multilayer HDPE package pigmented with $\mathrm{TiO}_{2}$ and carbon black protected milk better than a monolayer HDPE package pigmented with $\mathrm{TiO}_{2}$, clear PETE and PETE pigmented with $\mathrm{TiO}_{2}$ when stored under fluorescent light at $4^{\circ} \mathrm{C}$ for 7 d. They found the multilayer HDPE package protected milk quality and suffered only a $28 \%$ Rb loss. The particle size of $\mathrm{TiO}_{2}$ can be altered to affect color of light wavelengths transmitted (DuPont, 2007). Innovation in the use of $\mathrm{TiO}_{2}$ particle size and refraction properties may improve packaging materials for milk quality protection.

Almost 30 yr ago, White (1985) evaluated consumer $(\mathrm{n}=393)$ response to pigmented HDPE packaging options [opaque white, cream colored, yellow, and a natural (translucent)] for milk; opaque white packaging was most frequently selected as the preferred package if no additional cost was incurred. This study also indicated that most respondents $(75 \%)$ did not think product visibility was a concern, suggesting that pigmented packaging could be successful. Respondents were equally concerned about the effects of light on nutrition and flavor. This early study suggests that consumers are willing to consider packaging modifications that protect milk flavor and nutrient quality. However, little guidance is available to the industry to identify the level of $\mathrm{TiO}_{2}$ that is needed for milk quality protection.

The overall purpose of this research was to quantify performance of $\mathrm{TiO}_{2}$-dosed HDPE packaging on preserving milk sensory quality and oxidative stability through prevention or control of photochemically induced reactions.

The objective of this research was to determine changes in sensory characteristics, vitamin $(\mathrm{Rb})$ retention, and oxidative stability of $2 \%$ milk packaged in HDPE bottles with different $\mathrm{TiO}_{2}$ modifications up to $36 \mathrm{~d}$ of refrigerated $\left(3^{\circ} \mathrm{C}\right)$ storage under fluorescent lighting, simulating retail storage.

\section{MATERIALS AND METHODS}

\section{Packaging}

The HDPE bottle types were differentiated using commercially available titanium dioxide pigments contained within the bottle resin, yielding bottles with different levels of light protection. Four levels of $\mathrm{TiO}_{2}$ in HDPE (total of 5 packaging treatments) were tested, including $0 \%$ (translucent) serving as controls (light exposed: no light barrier; light protected: foil overwrap) and the 3 experimental $\mathrm{TiO}_{2}$-modified packaging treatment levels (low: 0.6\%; medium: 1.3\%; high: 4.3\%). Bottle dimensions were 7.16 " height $\times 3.29$ " width $\times$ 2.1 " depth and a volume of $528 \mathrm{~mL}$. We could readily see the milk in the control HDPE packages (translucent), but the visual appearance of the experimental $\mathrm{TiO}_{2}$-loaded packages was opaque white and prevented visualization of the milk. 


\section{Milk Processing}

We limited light exposure of milk from the point of raw milk collection, through processing and packaging until packaged milk was placed into the controlled lighting conditions. Fresh raw milk was obtained from the Virginia Tech dairy farm and processed in the Food Science and Technology dairy pilot plant within $24 \mathrm{~h}$ of collection. Raw milk was stored at $4^{\circ} \mathrm{C}$ until processing. Before pasteurization, milk was prewarmed $\left(55^{\circ} \mathrm{C}\right)$, separated into cream and skim milk using a pilot plant separator (model 1G, $6400 \mathrm{rpm}$, Bonanza Industries Inc., Calgary, Canada), and standardized to $2.0 \pm 0.1 \%$ fat (Babcock method, AOAC 989.04; Bradley, 2000). Milk was homogenized in a 2-stage homogenizer [10,339 $\mathrm{kPa}(1,500 \mathrm{psi})$ for the first stage; $3,446 \mathrm{kPa}$ (500 psi) for the second stage; Type DX, Cherry Burrell Corp., Delavan, WI] and UHT pasteurized at $131.1^{\circ} \mathrm{C}$ for $2 \mathrm{~s}$ (UHT/HTST Lab-25 DH pasteurizer, MicroThermics, Raleigh, NC). Milk was chilled for $24 \mathrm{~h}$, then filled into clean 528-mL (16-oz) HDPE bottles and sealed with a screw cap lid. Prior to filling, bottles were sanitized with $100 \mathrm{mg} / \mathrm{kg}$ of chlorine solution, rinsed with deionized $\mathrm{dH}_{2} \mathrm{O}$, and drained. Approximately $470 \mathrm{~mL}$, leaving $58 \mathrm{~mL}$ of headspace, was dispensed to each bottle using a Wheaton Unispense II (Wheaton Instruments, Millville, NJ). Milk was clean-filled into packages under a positive laminar flow hood (Atmos-Tech Industries, Ocean, NJ). During the bottling process, filled bottles were stored in iced coolers to control temperature until transferred to the retail storage case.

\section{Storage Conditions}

Samples were stored in refrigerated conditions. For the first replication (block A), a refrigerated retail case (Friedrich Floating Air, Friedrich 60-10-1056, San Antonio, TX) was used to simulate retail conditions. The second replication (block B) was completed in a walk-in cooler (Tonka Inc., Hopkins, MI) because the refrigerated case failed under the conditions of summer heat.

The refrigerated retail case was glass fronted with 5 doors and 3 shelves in which 2 fluorescent light bulbs ran the length of the dairy case over each shelf at $1 / 5$ th and $4 / 5$ th the distance from the front of the shelf. Six fluorescent light bulbs were situated vertically at the front of the dairy case at the ends of the case and in between each door junction. From the top of the bottle to the bulbs at the top of each shelf was a distance of $11.4 \mathrm{~cm}$. The retail case was equipped with fluorescent cool white, 32-W light bulbs (Alto II, Panasonic, Maple Grove, MN) simulating retail conditions. Bottle placement within the dairy case was planned so that all treatments were distributed randomly to reduce effects of different lighting intensity within the case. Temperature and light intensity were measured routinely. The average temperature of the refrigerated case was $2.7^{\circ} \mathrm{C} \pm 0.8$. Over the 5 -wk storage study, light intensity measurements were taken in 3 general locations on each treatment for each day of analysis. Light intensity averaged 2,186 lx, with a range from 396 to $3,970 \mathrm{~lx}$, depending on sampling location. The randomization strategy for placing and removing of bottles was performed using JMP 10.0.0 Statistical Discovery Software (SAS Institute Inc., Cary, NC). Because of the broad range of light intensity, multiple bottles of each treatment and each control were randomly selected on each day of analysis for evaluation. For replication 1, samples were removed from the lighted case on d 1,3 , $8,15,22$, and 29 for both sensory and chemical testing; in addition, chemical analyses (only) were completed on d 36 and sensory evaluation (only) was completed on d 43 .

The walk-in cooler was equipped with 2 fluorescent lighting fixtures (2 bulbs each; $1.2 \mathrm{~m}$ length) positioned horizontally over each shelf to mimic the retail case; lights were positioned approximately $13 \mathrm{~cm}$ above milk packages. Samples were stored at an average lux and temperature of $2,421 \pm 551 \mathrm{~lx}$ and $3.0 \pm 0.9^{\circ} \mathrm{C}$, respectively. Replication 2 samples were tested on the same dates (through d 36) as the first replication; only chemical analyses were completed in this replication.

For each day of analysis, bottles from each treatment were withdrawn from the refrigerated storage unit and evaluated as described below. For the first replication (block A), 10 bottles were randomly selected. Two of these bottles were tested for analytical analyses; the remaining product from the tested bottles plus the other 8 bottles were commingled for sensory testing. For the second replication (block B), 2 bottles were randomly selected for analytical assays; no sensory testing was completed in this replication. A total of 4 bottles (2 from block A; 2 from block B) were evaluated for each treatment on each day of evaluation. Values for each packaging treatment for each day were averaged for each method of analysis.

\section{Microbial Analysis}

Standard plate counts of aerobic organisms were performed based on standard methods to ensure milk samples were properly pasteurized and maintained satisfactory microbial quality over the storage period (Laird et al., 2004). Samples were plated using Petrifilm Aerobic Count Plates (3M, St. Paul, MN). Aerobic count plates were incubated at $32 \pm 1^{\circ} \mathrm{C}$ for $48 \pm 3 \mathrm{~h}$. Microbial tests were conducted on $\mathrm{d} 0$ and $2 \mathrm{~d}$ before sensory tests. 


\section{Degradation of Rb by Fluorometric Analysis}

The $\mathrm{Rb}$ concentration in milk was analyzed using the fluorometric method (AOAC method 970.65; Bradley, 2000; Webster et al., 2009) and was measured on a Shimadzu RF-1501 spectrofluorophotometer (Shimadzu Scientific Instrument Inc., Columbia, MD). Samples were prepared by adding $0.01 \mathrm{~N}$ hydrochloric acid to milk $(10 \mathrm{~mL})$ to $\mathrm{pH}$ between 5.0 and 6.0. Hydrochloric acid $(10 \mathrm{~N}, 0.1 \mathrm{~mL})$ was added and the sample was autoclaved under pressure $(117 \mathrm{kPa})$ for $30 \mathrm{~min}$ at 121 to $123^{\circ} \mathrm{C}$. Samples were cooled and $\mathrm{pH}$ adjusted between 6.0 and 6.5 using $0.025 \mathrm{~N}$ sodium hydroxide. Hydrochloric acid $(0.1 \mathrm{~N})$ was immediately added to stop further precipitation around $\mathrm{pH}$ of 4.5 . Each sample was then filtered using $25 \mathrm{~mm}$ syringe with a $0.2-\mu \mathrm{m}$ filter (Grace, Deerfield, IL) and 10-mL Norm-Ject syringe (Henke Sass Wolf Inc., Tuttlingen, Germany) before being measured using the spectrofluorophotometer.

\section{Secondary Oxidation By-Products by Thiobarbituric Acid Reactive Substance Analysis}

Thiobarbituric acid reactive substances (TBARS) were used to ascertain the development of malondialdehyde and other aldehydes, which are secondary oxidative products of fatty acids. This oxidative product reacts with thiobarbituric acid and creates a reddish/ pink color, which can be read spectrophotometrically. The TBARS method was adapted according to Spanier and Taylor (1991). Samples (1 mL) from each treatment and control were diluted 1:4 ratio by adding 4 $\mathrm{mL}$ of distilled $\mathrm{H}_{2} \mathrm{O}$. Diluted sample was vortexed for approximately $20 \mathrm{~s}$, and $1 \mathrm{~mL}$ was pipetted into a disposable centrifuge tube $(15 \mathrm{~mL})$ with SDS solution (4 $\mathrm{mL}$ ) and EDTA solution $(0.1 \mathrm{~mL})$. Samples were mixed via vortex for $20 \mathrm{~s}$ and incubated in a water bath $\left(95^{\circ} \mathrm{C}\right.$, $60 \mathrm{~min}$ ), cooled to room temperature in an iced water bath, then mixed with pyridine and butanol solution. Samples were centrifuged for $20 \mathrm{~min}$ at room temperature at $1,600 \times g$. The top organic layer $(2.5 \mathrm{~mL})$ was carefully transferred into a $1.5-\mathrm{mL}$ polystyrene cuvette and absorbance read at $532 \mathrm{~nm}$ using a spectrophotometer (Spectronic 21D, Milton Roy, Ivyland, PA).

\section{Volatile Chemistry by GC-MS}

To help identify volatile compounds developed during storage, milk samples were analyzed for headspace volatiles. Replication 1 samples were analyzed within $24 \mathrm{~h}$ of sampling. Replication 2 samples were frozen at $-70^{\circ} \mathrm{C}$, thawed slowly in the refrigerator, and analyzed. Volatile compounds from milk were adsorbed on a solid- phase microextraction fiber (SPME; $85 \mu \mathrm{m}$ carboxenpolydimethyl siloxane SPME fiber, Supelco, Bellefonte, PA) and separated using gas chromatography (GC). An HP 5890 GC with 5972 series mass selective detector HP5MS (Hewlett Packard, Palo Alto, CA) was used to identify volatile headspace compounds. Samples $(8$ $\mathrm{mL}$ ) from each treatment and control were pipetted into 20-mL amber vials. Volatiles were adsorbed onto a clean polydimethyl siloxane SPME fiber. The fiber was exposed $(4 \mathrm{~mm})$ to sample headspace for $20 \mathrm{~min}$ with heating to $45^{\circ} \mathrm{C}$ (RCT basic heater with an ETSD4 Fuzzy Controller, IKA Werke, Wilmington, NC) and agitation $(250 \mathrm{rpm})$. Volatiles were desorbed from the fiber onto a DB-5 capillary column $(30 \mathrm{~m} \times 0.25$ $\mathrm{mm}$ i.d. $\times 0.25 \mu \mathrm{m}$ film thickness; J\&W Scientific, Folsom, CA), separated and analyzed using the following conditions: helium gas flow: $1.8 \mathrm{~mL} / \mathrm{min}$; injector temperature: $280^{\circ} \mathrm{C}$; and detector temperature: $280^{\circ} \mathrm{C}$. An initial run temperature rate of $35^{\circ} \mathrm{C}$ was held for 0.5 min and then the temperature was increased by $15^{\circ} \mathrm{C} /$ min to $180^{\circ} \mathrm{C}$ and held for $0.5 \mathrm{~min}$. The temperature then was increased by $20^{\circ} \mathrm{C} / \mathrm{min}$ to $260^{\circ} \mathrm{C}$ with the final temperature held for $0.5 \mathrm{~min}$. The total run time was $15.17 \mathrm{~min}$ and the program ran in split-less mode. Chromatograms were plotted using HP ChemStation software (Hewlett Packard, Palo Alto, CA). External standards of pentanal and hexanal in $\mathrm{dH}_{2} \mathrm{O}$ were used to identify oxidation products.

\section{Sensory Analyses}

Sensory analysis was performed by triangle tests (Meilgaard et al., 2007) on each day of evaluation (replication 1). Milk (10 packages; commingled) from each $\mathrm{TiO}_{2}$-modified package treatment was compared with light-protected milk (100\% opacity, 20 packages, commingled), testing for similarity to determine if the treatment provided equivalent and adequate protection as the light-protected product. Statistical parameters for similarity were $\alpha=0.10, \beta=0.05$, with an estimated proportion of discriminators $\left(\mathbf{p}_{\mathrm{d}}\right)$ of $30 \%$. In addition, following the same sampling plan, milk from each $\mathrm{TiO}_{2}$-modified package was compared with lightexposed milk to determine if a difference could be detected between samples based on protection of the product by the packaging material. Statistical parameters for difference testing were $\alpha=0.05, \beta=0.10$, and the estimated $\mathrm{p}_{\mathrm{d}}$ of $30 \%$.

Virginia Tech Institutional Review Board approval was obtained before the beginning of the study. Informed consent was obtained from a minimum of 98 panelists who were recruited via email. To avoid sensory fatigue, an incomplete block design was used; panelists were 
presented with three 3-sample (triangle) sets on each day of evaluation. Each sample set included 3 numerically coded (3-digit) samples $\left(30 \mathrm{~mL} ; 4^{\circ} \mathrm{C}\right)$. Panelists were told that 2 samples were identical and 1 sample was different. Panelists were asked to smell and taste each sample from left to right and record which sample they perceived to be the different sample. Water was provided to rinse between sessions and to limit sensory fatigue; a rest time of $1 \mathrm{~min}$ was established between each sample set.

Sensory testing was conducted in the FST Sensory Laboratory. Panelists each worked in a partitioned booth, under white light, and provided responses on a touchscreen monitor. Sensory Information Management Systems (SIMS 2000, Sensory Computer Management, Morristown, NJ) software was used to record responses and analyze the data.

\section{Statistical Analysis}

A 2-way factorial ANOVA with repeated measures (time; $\mathrm{n}=7 \mathrm{~d}$ of testing), with blocking for the experimental blocks (replication 1 and 2), was used to assess changes in oxidation. Main effects and interactions were tested at $\alpha=0.05$. Analytical analyses for TBARS and $\mathrm{Rb}$ were completed on each day of evaluation on 2 bottles of each treatment with duplicate samples evaluated from each bottle for each method. Volatile analysis was completed on each sample bottle (one evaluation). Statistical analyses were performed using JMP 10.0.0 Statistical Discovery Software (SAS Institute Inc., Cary, NC). Least significant difference contrast tests were used for mean separation when significant differences were found. Sensory data (replication 1) were analyzed based upon statistical parameters mentioned above and equations outlined in Meilgaard et al. (2007) by replication as well as for commingled data.

\section{RESULTS AND DISCUSSION}

Packages used in this project were not characteristic shape or wall thickness of a typical HDPE milk package. Therefore, although it is not possible to make a direct comparison of outcomes from this project to commercial packaging, we can learn about the relationship of $\mathrm{TiO}_{2}$ levels in HDPE for protecting milk flavor and nutrients from light. The $\mathrm{TiO}_{2}$ levels in our packaging ranged from $0 \%$ (translucent control) to $4.6 \%$ (high). Moyssiadi et al. (2004) used PET and HDPE packaging at $2 \%\left(20 \mathrm{~g} / \mathrm{kg}\right.$ of $\left.\mathrm{TiO}_{2}\right)$.

Although the refrigeration conditions were different between replications, blocks were not statistically different. This allows for comparison of packaging treatments over time.

\section{Protection of Sensory Quality}

The goal of this research was to determine if the $\mathrm{TiO}_{2}$ modifications provided better protection than a standard HDPE package (translucent control) and was comparable in protection to an optimum light barrier protection (foil-wrapped control). Therefore, the sensory testing was designed to minimize type I error (difference testing) when comparing the $\mathrm{TiO}_{2}$ packages against the translucent control package and to minimize type II (similarity testing) error in comparison with foil control. The actual power of the sensory test was high, ranging from 60 to $95 \%$, depending on the test design.

Table 1 describes the packaging success by providing the $P$-values for each package comparison over the product shelf-life. As expected, the difference between the foil and translucent control packages was noted early in the shelf life (d 3; $P=0.0002)$ and was consistently observed thereafter. High $\mathrm{TiO}_{2}$ protected better than translucent control $(P<0.05$; assumption that translucent control provides no protection) throughout the shelf-life as illustrated by difference testing. The medium and low $\mathrm{TiO}_{2}$ packages did not provide greater protection than the translucent control in the first week, but sensory differences were noted by $\mathrm{d} 8$. This suggests that, whereas milk in these packages did undergo oxidation early in the shelf-life, the oxidation rate over the extended storage period was lower in the milk in the low and medium $\mathrm{TiO}_{2}$ packaging than that of the milk in the translucent control package.

The high $\mathrm{TiO}_{2}$ package provided the best protection of the experimental packages, as indicated by similarity testing against the light-protected control. This package provided protection at a level equivalent to the light-protected control through d 29 and possibly longer; however, a difference was observed on d 43. An exception occurred on $\mathrm{d} 8$, when the tested population discerned the difference between the high $\mathrm{TiO}_{2}$ and light-protected package, with $31 \%$ correctly identifying the difference; the proportion of discriminators on that date was calculated as 10 to $52 \%$ of the true population able to find the difference. This marginally surpassed the preset proportion of discriminators $(30 \%)$ and may have been attributed to a chance disproportionate number of experienced participants in the panel on that day.

With the exception of $\mathrm{d} 15$, the other $2 \mathrm{TiO}_{2}$ treatments (low, medium) were statistically different $(P<$ $0.05)$ from light-protected control, indicating that they did not protect the milk from off flavors or aromas as well as full light protection. As previously noted, milk within low and medium packages was different from light-exposed control milk by d 8. Distinguishing that the packaging yields a sensory difference from the 
Table 1. Summary of statistical significance of sensory testing (triangle tests) for $2 \%$ milk packaged in high-density polyethylene (HDPE) with different $\mathrm{TiO}_{2}$ experimental levels (low, medium, high) compared with controls (light exposed, LE); light protected (LP) over 43 d of light exposure $(2,186 \mathrm{~lx})$ at $3^{\circ} \mathrm{C}^{1}$

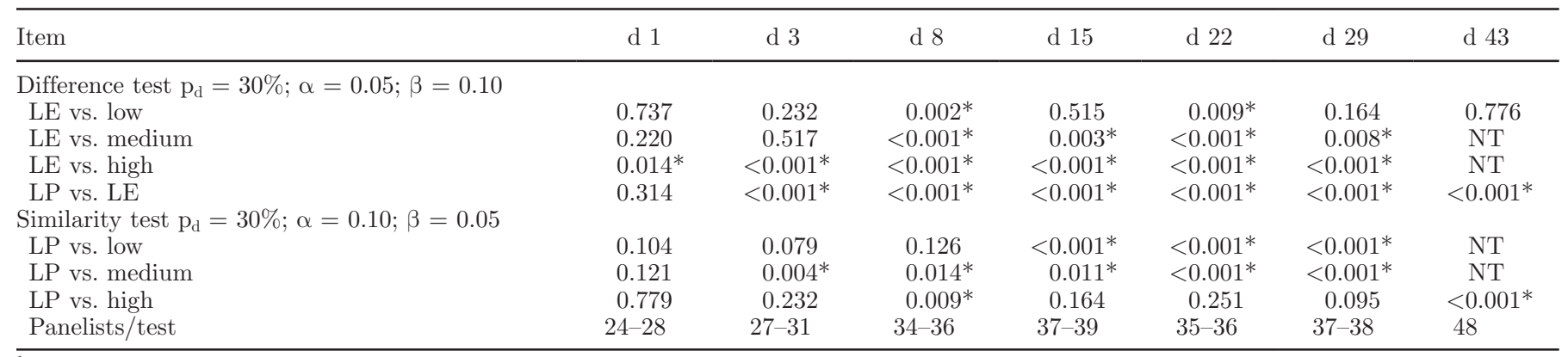

${ }^{1}$ Dosage of $\mathrm{TiO}_{2}$-HDPE modified packaging [low $\left(0.6 \% \mathrm{TiO}_{2}\right)$, medium $\left(1.3 \% \mathrm{TiO}_{2}\right)$, high $(4.3 \% \mathrm{TiO})$ ]. Controls: light-protected (HDPE with foil overwrap); light-exposed (HDPE bottles with no $\mathrm{TiO}_{2}$ or foil). $\mathrm{NT}=$ not tested because the difference had already been established. The d-36 evaluation period occurred during university spring break and the local population at that time was not sufficient to complete the testing. Therefore, an additional day ( $\mathrm{d} 43$ ) of testing was included for those tests needing further data. $\mathrm{p}_{\mathrm{d}}=$ proportion of discriminators.

$* P<0.05$.

translucent control milk product does not guarantee that milk flavor is sufficiently protected. However, evaluating for similarity to the milk in the light-protected (foil) control provided that validation. The low and medium $\mathrm{TiO}_{2}$ packages provided no significant protection; milk from those packages was different from the light-protected milk by the third day. However, the high $\mathrm{TiO}_{2}$ package provided protection equivalent to the light-protected milk through d 29 with an anomaly on $\mathrm{d} 8(P=0.0085)$.

The sensory work was completed on milk that was commingled from 10 different packages for each treatment. Analytical assessment was not completed on the commingled milk. It is probable that the averages reported for the analytical assessments described below are representative of the packaging treatments but may not be the exact values for the commingled milk that was evaluated by sensory testing.

\section{Vitamin Retention}

Riboflavin, also known as vitamin $\mathrm{B}_{2}$, is a watersoluble vitamin found in large amounts in milk at an average concentration between 1.36 and $1.75 \mathrm{mg} /$ mL (Dimick, 1982; Zygoura et al., 2004). The average initial $\mathrm{Rb}$ concentration in milk for this study was below that level $(0.73 \mathrm{mg} / \mathrm{mL})$ for both replications; all $\mathrm{Rb}$ values throughout the study were at that level or decreased with time and light exposure. Vallet et al. (2013) reported that $\mathrm{Rb}$ concentration in milk is affected by bovine nutrition. The milk used in this study was from the Virginia Tech dairy herd, which is often used for nutrition studies; we do not have direct knowledge of the herd nutritional management during the time of this study. Thus, we reported $\mathrm{Rb}$ as \% retention
(Figure 1) over time, to illustrate the efficacy of the packaging for protecting $\mathrm{Rb}$.

Riboflavin degradation is undesirable in food systems because it decreases the nutritional value of the food (Hoskin, 1988). Riboflavin concentration in milk decreased over the $36 \mathrm{~d}$ of evaluation in all packages (Figure 1). Riboflavin in milk from the light-protected treatment did not change significantly $(P>0.05)$, with only a $10.5 \%$ relative loss of $\mathrm{Rb}$ over the 5 -wk storage period. Milk packaged in the high $\mathrm{TiO}_{2}$ package maintained high level of $\mathrm{Rb}$, comparable with the lightprotected control through d 22, but had more rapid Rb degradation from d 22 through d 36 (28\% decrease overall from d 1; $P<0.05)$. Riboflavin concentration in milk in the high $\mathrm{TiO}_{2}$-package was significantly higher $(<0.05)$ than in translucent control bottles by d 3 . The low and medium $\mathrm{TiO}_{2}$ packages protected $\mathrm{Rb}$ through $15 \mathrm{~d}$ of storage $(P>0.05$; contrast to $\mathrm{d} 1)$. The medium $\mathrm{TiO}_{2}$ packages retained $60 \% \mathrm{Rb}$ through the storage period (d 36), whereas the low $\mathrm{TiO}_{2}$ and light-exposed control packages permitted 60 to $76 \%$ Rb degradation by $\mathrm{d} 36$.

The degradation of $\mathrm{Rb}$ due to light exposure is well studied (Dimick, 1973; Hoskin and Dimick, 1979; Christy et al., 1981; Hoskin, 1988; Moyssiadi et al., 2004; Webster et al., 2009). Webster et al. (2009) reported a loss of total Rb between 52.6 and $67.5 \%$ in $2 \%$ milk in light-exposed and specialized film packaging treatments within $3 \mathrm{~d}$ of refrigerated storage; at the end of the study ( $21 \mathrm{~d}$ ), 95 to $98 \%$ of the Rb was degraded. In the current study, the relationship between packaging protection of $\mathrm{Rb}$ closely relates to the observed sensory protection with the high $\mathrm{TiO}_{2}$ providing photo-protection of Rb, thus limiting the onset of photo-induced oxidation. In this study we have shown that white 


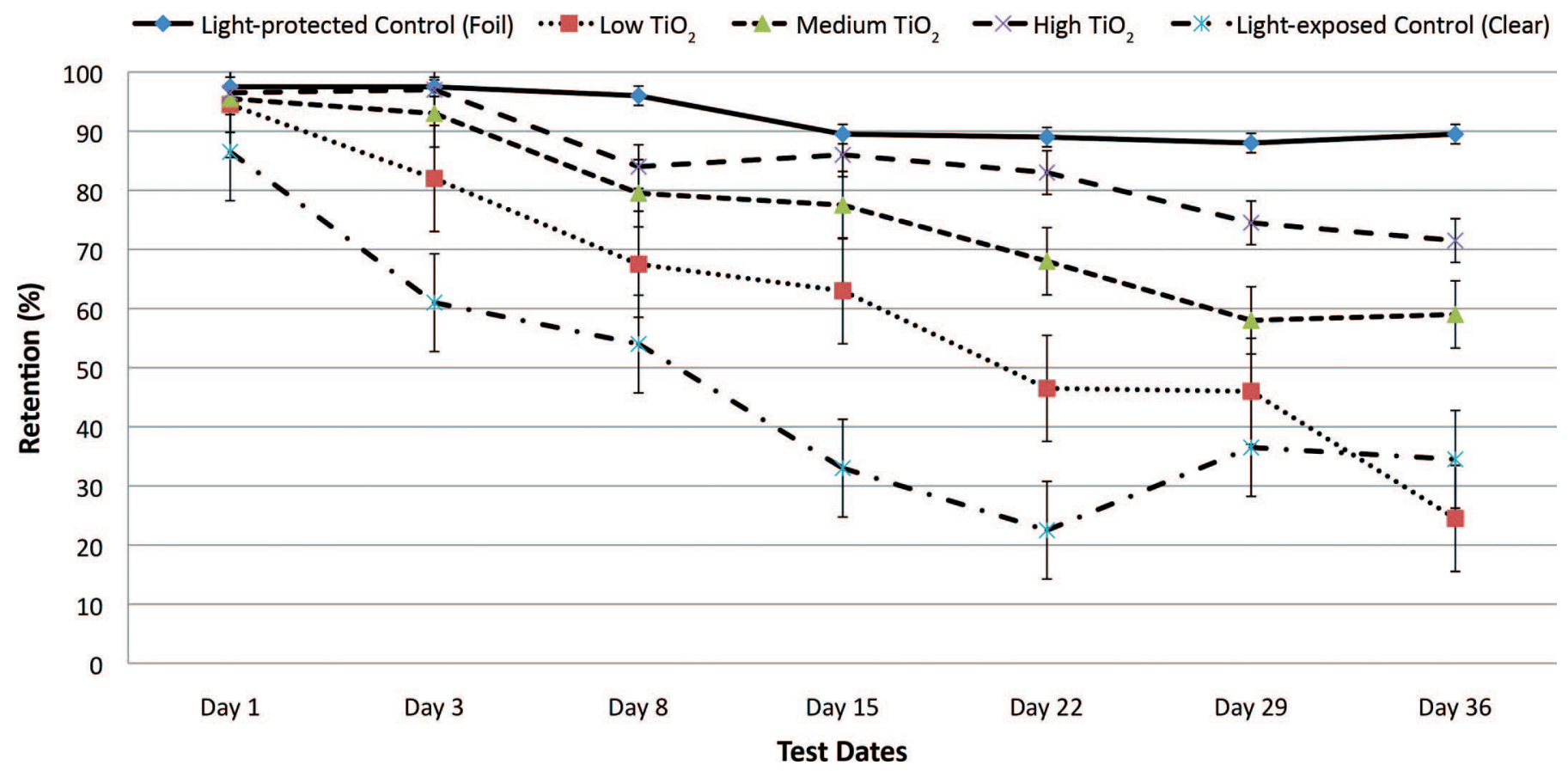

Figure 1. Riboflavin retention in milk (2\% milkfat) packaged in $\mathrm{TiO}_{2}$-loaded $\left[\right.$ low $\left(0.6 \% \mathrm{TiO}_{2}\right) ;$ medium $\left(1.3 \% \mathrm{TiO}_{2}\right) ;$ high $(4.6 \% \mathrm{TiO})$ ] high-density polyethylene (HDPE) compared with light-exposed (translucent; natural $\mathrm{HDPE}$ with no $\mathrm{TiO}_{2}$ ) and light-protected (foil wrapped; natural $\mathrm{HDPE}$ with no $\left.\mathrm{TiO}_{2}\right)$ packaging. Packages were stored at an average light intensity of $2,304 \pm 166 \mathrm{~lx}$ over $36 \mathrm{~d}\left(3^{\circ} \mathrm{C}\right)$. The average initial riboflavin concentration was $0.73 \mathrm{mg} / \mathrm{mL}$. Mean values $( \pm \mathrm{SE})$ for each packaging treatment on each day were based on 2 replications of 2 bottles each. Color version available online.

opaque package appearance, as perceived visually, is insufficient to indicate appropriate protection of nutrients from the effects of light exposure. This study illustrates that LPA additives, such as $\mathrm{TiO}_{2}$, in HDPE must be added at a level sufficient to protect Rb during retail storage, thus providing greater protection of milk flavor and nutrients. The $\mathrm{TiO}_{2}$ added at $0.6 \%$ to HDPE did not provide sufficient protection for light exposure longer than $24 \mathrm{~h}$ in our study, although it must be considered that the packages used in this study were not the shape or wall thickness of fluid milk packaging.

\section{Control of Oxidation}

The TBARS assessment of MDA and other aldehydes has been studied extensively in meat and milk oxidation and shown to increase in concentration as photooxidation of milk occurs (Rosenthal et al., 1993; van Aardt et al., 2005; Campo et al., 2006). Thiobarbituric acid reactive substances have also been shown to correlate with changes in sensory characteristics of light-induced oxidation (Rosenthal et al., 1993). Rosenthal et al. (1993) reported levels of TBARS $(0.61 \mathrm{mg} / \mathrm{L})$ for whole milk that was stored in the dark for $7 \mathrm{~d}$. Milk in this study had initial values in the same range $(0.68 \mathrm{mg} / \mathrm{L})$. Campo et al. (2006) estimated that a TBARS value around $2 \mathrm{mg} / \mathrm{L}$ can be the limiting threshold for the acceptability of oxidized rancidity flavor in beef but no definite value for TBARS has been defined for acceptability of flavor in milk.

As expected, light-protected packaging provided optimal oxidative control (Figure 2); aldehyde production was lowest in this group and did not increase significantly $\left(P>0\right.$. 05) over time. Milk in the high $\mathrm{TiO}_{2}$ package had TBARS values similar to $(P>0.05)$ the light-protected control up to d 29. However, by d 36, aldehyde production increased more rapidly than in the milk from the light-protected control package $(P$ $<0.05)$, although still significantly lower than lightexposed milk control. This closely approximates the trends of $\mathrm{Rb}$ concentration. The TBARS increased by d 8 in the other packages to values exceeding $1.0 \mathrm{mg} / \mathrm{L}$.

We observed that differences in TBARS values closely related to the observed differences in sensory evaluation. All significant statistical contrasts for sensory comparisons had TBARS values of $1.3 \mathrm{mg} / \mathrm{L}$ or greater with 2 exceptions very early in the shelf-life. On d 36 aldehyde concentrations in the high $\mathrm{TiO}_{2}$ package $(1.43$ $\mathrm{mg} / \mathrm{L})$ and light-protected control $(1.0 \mathrm{mg} / \mathrm{L})$ were significantly different between the 2 samples. It can be inferred that TBARS values in milk greater than 1.3 $\mathrm{mg} / \mathrm{L}$ may be indicative of perceptible sensory changes 


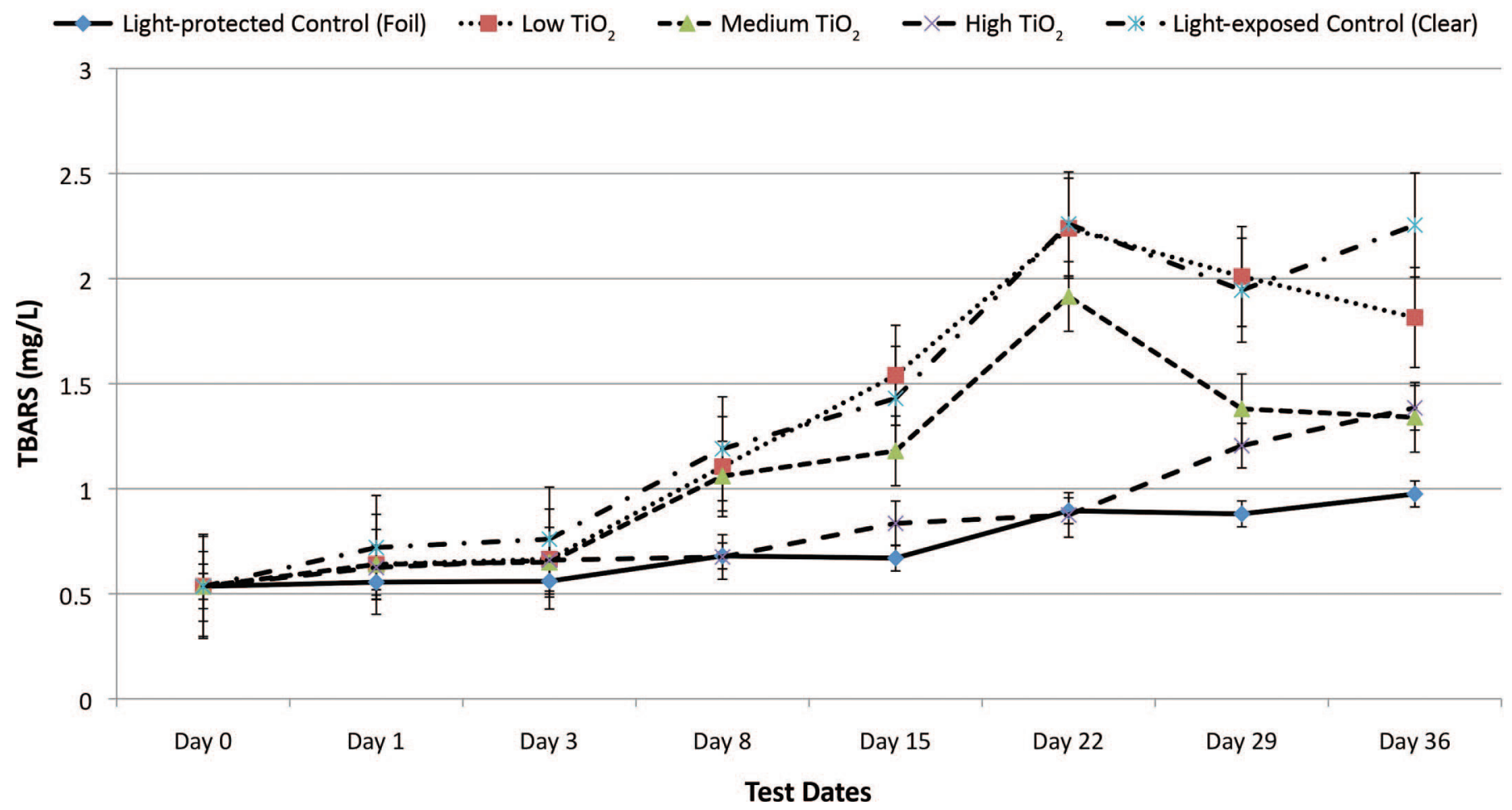

Figure 2. Thiobarbituric acid reactive substances (TBARS) concentration in milk (2\% milkfat) packaged in $\mathrm{TiO}_{2}-$ loaded $\left[\right.$ low $\left(0.6 \% \mathrm{TiO}_{2}\right)$; medium $\left(1.3 \% \mathrm{TiO}_{2}\right)$; high $\left(4.6 \% \mathrm{TiO}_{2}\right)$ ] high-density polyethylene (HDPE) compared with light-exposed (translucent; natural HDPE with no $\mathrm{TiO}_{2}$ ) and light-protected (foil wrapped; natural $\mathrm{HDPE}$ with no $\mathrm{TiO}_{2}$ ) packaging. Packages were stored at an average light intensity of $2,304 \pm$ $166 \mathrm{~lx}$ over $36 \mathrm{~d}\left(3^{\circ} \mathrm{C}\right)$. The average initial TBARS value was $0.55 \mathrm{mg} / \mathrm{L}$. Mean values $( \pm \mathrm{SE})$ for each packaging treatment on each day were based on 2 replications of 2 bottles each. Color version available online.

from light-induced oxidation. This does not directly imply a change in sensory acceptability of milk, but may imply a notable change in sensory quality.

Numerous volatile compounds are produced during photooxidation. Pentanal and hexanal are common secondary lipid oxidative compounds found in milk (Mehta and Bassett, 1978; Farrer, 1983; Bekbolet, 1990; Cadwallader and Howard, 1998; Rysstad et al., 1998; van Aardt et al., 2001, 2005; Mestdagh et al., 2005; Webster et al., 2009, 2011; Moore et al., 2012) and are commonly used as indicators of lipid oxidation. In this study, several compounds (pentanal, hexanal, dimethyl disulfide, and 2-propanone) increased in peak area over time (data not shown for pentanal, dimethyl disulfide, and 2-propanone). Hexanal peak area was statistically significantly higher $(P<0.05)$ in light-exposed control than the light-protected treatment by d 15 and this finding remained true through d 36 (Figure 3). Hexanal concentration (based on peak area) in milk was not significantly different among $\mathrm{TiO}_{2}$ packaging treatments through d 29 of the experiment. However, several treatments were significantly lower in hexanal than the light-exposed control on several days of the experiment. The medium and high $\mathrm{TiO}_{2}$ treatments appeared to limit hexanal production, relative to the light-protected control. Webster et al. (2009) also reported that hexanal was a major volatile peak in light exposed milk. Their study used film overwraps that provided light interference targeted at the major wavelengths of $\mathrm{Rb}$. The light interference films limited the development of hexanal compared with light-exposed control milk (no film overwraps), but were not as effective as the light-protected (foil overwrap) control (Webster et al., 2009). However, in our current project, we did observe a longer delay in hexanal development, through $8 \mathrm{~d}$, with the HDPE with $\mathrm{TiO}_{2}$ compared with the light interference overwrap films used in the study by Webster et al. (2009), which showed increases in hexanal by $8 \mathrm{~d}$.

Statistical contrasts for hexanal (data not shown) were similar to the results of the Rb analysis. No significant differences were observed in hexanal peak area in high $\mathrm{TiO}_{2}$-packaged milk through d 29 compared with d 1. On d 36, milk in the high $\mathrm{TiO}_{2}$ packages had higher hexanal production compared with light-protected control milk. The light-exposed control and low $\mathrm{TiO}_{2}$ package were unable to control hexanal production; the medium $\mathrm{TiO}_{2}$ packaging was more effective than the 


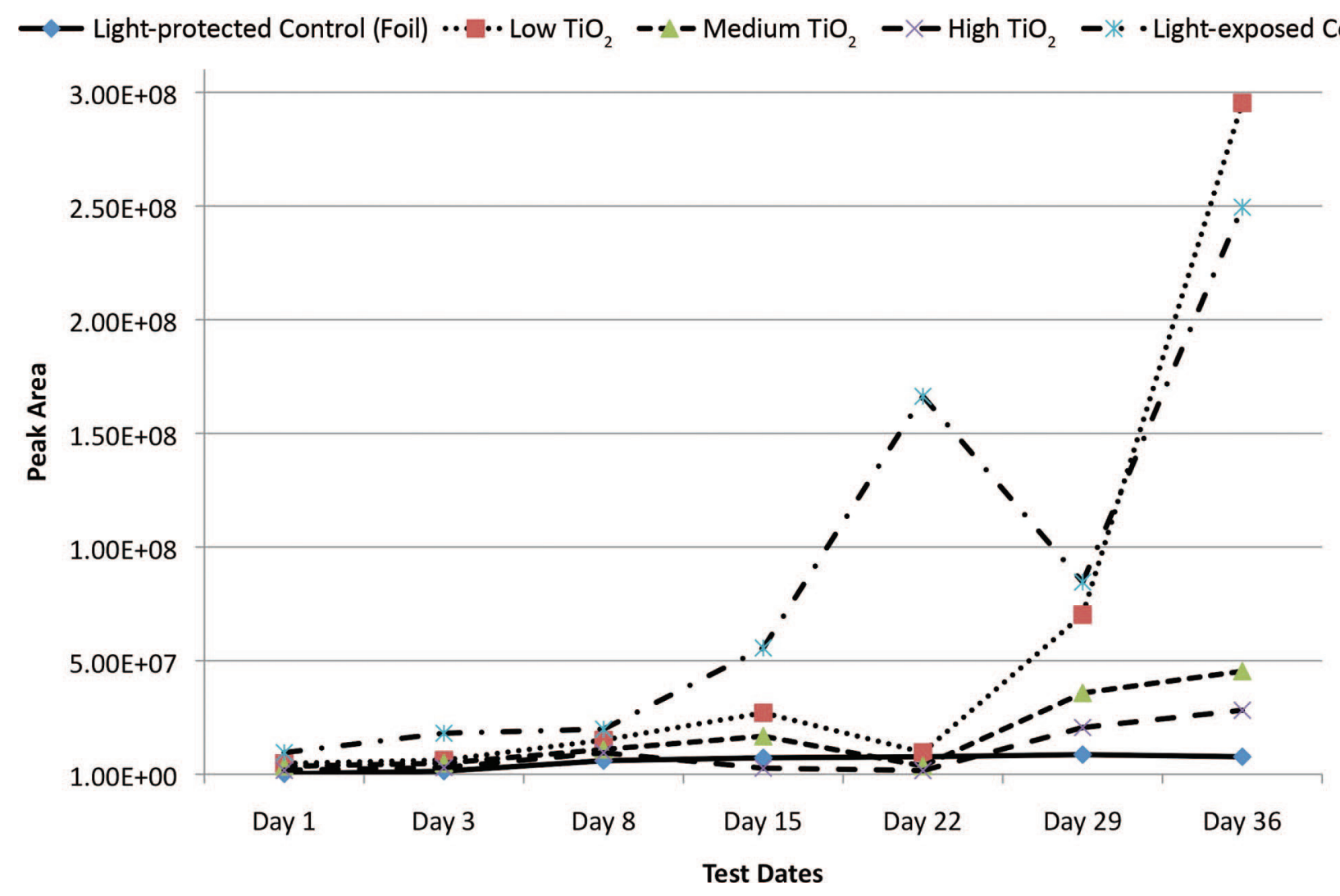

Figure 3. Hexanal concentration in milk (2\% milkfat) packaged in $\mathrm{TiO}_{2}$-loaded [low $\left(0.6 \% \mathrm{TiO}_{2}\right) ;$ medium $\left(1.3 \% \mathrm{TiO}_{2}\right) ;$ high $(4.6 \% \mathrm{TiO})$ ] high-density polyethylene (HDPE) compared with light-exposed (translucent; natural HDPE with no $\mathrm{TiO}_{2}$ ) and light-protected (foil wrapped; natural $\mathrm{HDPE}$ with no $\mathrm{TiO}_{2}$ ) packaging. Packages were stored at an average light intensity of $2,304 \pm 166 \mathrm{~lx}$ over $36 \mathrm{~d}\left(3^{\circ} \mathrm{C}\right)$. Mean values for each packaging treatment on each day based on 2 replications of 2 bottles each. Color version available online.

low $\mathrm{TiO}_{2}$ packaging but not as effective as the high $\mathrm{TiO}_{2}$ packaging.

\section{CONCLUSIONS}

Not all visually opaque milk packaging effectively protects milk nutrients and flavor over an ESL period. Packaging can be modified to protect milk sensory quality and control photo-oxidation of $\mathrm{Rb}$ by manipulating photo-responsive molecules in the packaging. Levels of $\mathrm{TiO}_{2}$ greater than $1.3 \%$ incorporated with HDPE resin during package production may effectively protect milk quality during an extended period of retail lighting exposure. A TBARS of $1.3 \mathrm{mg} / \mathrm{L}$ or higher is indicated as a marker of milk sensory quality changes due to light exposure. The dairy industry can use this information to assist with packaging selection to improve fluid milk quality for ESL fluid milk.

\section{ACKNOWLEDGMENTS}

This project was funded in part by DuPont (Wilmington, DE), the Virginia Agricultural Experiment
Station (Blacksburg), and the Hatch Program of the National Institute of Food and Agriculture, US Department of Agriculture.

\section{REFERENCES}

Bekbolet, M. 1990. Light effects on food. J. Food Prot. 53:430-440. Boff, J. M., and D. B. Min. 2002. Chemistry and reaction of singlet oxygen in foods. Comprehensive Rev. Food Sci. Food Safety 1:58-72.

Bradley, R. L. 2000. Dairy Products. 1-83 in Official Methods of Analysis of AOAC Int. Vol. II. 17th ed. W. Horwitz, ed. AOAC Int., Gaithersburg, MD.

Cadwallader, K. R., and C. L. Howard. 1998. Analysis of aroma-active components of light activated milk. pp 343-358 in Flavor Analysis: Developments in Isolation and Characterization/ACS Symposium Series No. 700. Am. Chem. Soc., Washington, DC.

Campo, M. M., G. R. Nute, S. I. Hughes, M. Enser, J. D. Wood, and R. I. Richardson. 2006. Flavour perception of oxidation in beef. Meat Sci. 72:303-311.

Chapman, K. 2002. New study validates light blocking efforts: Teens taste light-oxidization in milk and don't like it. Dairy Foods 103:40-42.

Chapman, K. W., L. J. Whited, and K. J. Boor. 2002. Sensory threshold of light-oxidized flavor defects in milk. J. Food Sci. 67:27702773 .

Christy, G. E., G. F. Amantea, and R. E. T. Irwin. 1981. Evaluation of effectiveness of polyethylene overwraps in preventing light-induced 
oxidation of milk in pouches. Can. Inst. Food Sci. Technol. J. 14:135.

Dimick, P. S. 1973. Effect of fluorescent light on the flavor and selected nutrients of homogenized milk held in conventional containers. J. Milk Food Technol. 36:383-387.

Dimick, P. S. 1982. Photochemical effects on flavor and nutrients of fluid milk. Can. Inst. Food Sci. Technol. J. 15:247-256.

Duncan, S. E., and H. H. Chang. 2012. Implications of light energy on food quality and packaging selection. Adv. Food Nutr. Res. $67: 25-73$

Duncan, S. E., and S. Hannah. 2012. Light-protective packaging materials for foods and beverages. Chapter 15 in Emerging Food Packaging Technologies: Principles and Practice. K. L. Yam and D. S. Lee, ed. Woodhead Publishing Ltd., Philadelphia, PA.

Duncan, S. E., and J. B. Webster. 2010. Oxidation and protection of milk and dairy products. Chapter 4. In Oxidation in Foods and Beverages and Antioxidant Applications: Management in Different Industry Sectors (Volume 2). E. Decker, R. Elias, and D. J. McClements, ed. Woodhead Publishing Ltd., Philadelphia, PA.

DuPont. 2007. Polymers, Light and the Science of $\mathrm{TiO}_{2}$. DuPont, Wilmington, DE

Farrer, K. T. H. 1983. Light damage in milk: A comparison of the protective properties of paperboard cartons and plastic bottles. Farrer Consultants, Blackburn, Victoria, Australia.

Heer, A. K., S. E. Duncan, and D. Brochetti. 1995. Sensory evaluation of and consumer response to off-flavor in milk. Dairy Food and Environ. Sanitation 15:488-493.

Hoskin, J. C. 1988. Effect of fluorescent light on flavor and riboflavin content of milk held in modified half-gallon containers. J. Food Prot. 51:19-23.

Hoskin, J. C., and P. S. Dimick. 1979. Evaluation of fluorescent light on flavor and riboflavin content of milk held in gallon returnable containers. J. Food Prot. 42:105-109.

Kyte, J. 1995. Mechanisms in Protein Chemistry. Garland Publishing Inc., New York, NY.

Laird, D. T., S. A. Gambrel-Lenarz, F. M. Scher, T. E. Graham, and R. Reddy. 2004. Microbiological count methods. Page 153 in Standard Methods for the Examination of Dairy Products. 17th ed. H. M. Wehr and J. F. Frank, ed. American Public Health Association, Washington, DC.

Mehta, R. S., and R. Bassett. 1978. Organoleptic, chemical and microbiological changes in ultra-high-temperature sterilized milk stored at room temperature. J. Food Prot. 41:806-810.

Meilgaard, M. C., G. V. Civille, and B. T. Carr. 2007. Sensory Evaluation Techniques. 4th ed. CRC Press, New York, NY.

Mestdagh, F., B. Meulenaer, J. Clippeleer, F. F. Devlieghere, and A. A. Huyghebaert. 2005. Protective influence of several packaging materials on light oxidation of milk. J. Dairy Sci. 88:499-510.

Moore, R. L., S. E. Duncan, A. Rasor, W. N. Eigel, and S. F. O'Keefe. 2012. Oxidative stability of an extended shelf-life dairy-based beverage system designed to contribute to heart health. J. Dairy Sci. 95:6242-6251.
Moyssiadi, T., A. Badeka, E. Kondyli, T. Vakirtzi, I. Savvaidis, and G. K. Kontominas. 2004. Effect of light transmittance and oxygen permeability of various packaging materials on keeping quality of low fat pasteurized milk: Chemical and sensorial aspects. Int. Dairy J. 14:429-436.

Robertson, G. L. 2006. Food Packaging Principles and Practices. 2nd ed. Taylor and Francis, New York, NY.

Rosenthal, I., B. Rosen, and S. Bernstein. 1993. Effects of milk fortification with ascorbic acid and iron. Milchwissenschaft 48:676-679.

Rysstad, G., A. Ebbesen, and J. Eggestad. 1998. Sensory and chemical quality of UHT-milk stored in paperboard cartons with different oxygen and light barriers. Food Addit. Contam. 15:112-122.

Sattar, A., J. M. deMan, and U. C. Alexander. 1976. Stability of edible oils and fats to fluorescent light irradiation. J. Am. Oil Chem. Soc. 53:473-477.

Spanier, A. M., and R. D. Taylor. 1991. A rapid, direct chemical assay for the quantitative determination of thiobarbituric acid reactive substances in raw, cooked, and cooked/stored muscles foods. J. Muscle Foods 2:165-176.

Vallet, J., S. Laverroux, C. Chaissing, C. Girard, C. Agabriel, B. Martin, and B. Graulet. 2013. Variations des teneurs en riboflavine du lait de vache selon les conditions de production. Nutr. Clin. Metab. 27:57S.

van Aardt, M., S. E. Duncan, J. E. Marcy, T. E. Long, and C. R Hackney. 2001. Effectiveness of poly(ethylene terephthalate) and high-density polyethylene in protection of milk flavor. J. Dairy Sci. 84:1341-1347.

van Aardt, M., S. E. Duncan, J. E. Marcy, T. E. Long, S. F. O'Keefe and S. R. Nielsen-Sims. 2005. Effect of antioxidant ( $\alpha$-tocopherol and ascorbic acid) fortification on light-induced flavor of milk. J. Dairy Sci. 88:872-880.

Walsh, A. M., H. Potts, and S. Duncan. 2014. Light exposure affects milk acceptability and emotional response of college students. J. Dairy Sci. 97(E. Suppl.):509. (Abstr.)

Webster, J. B., S. E. Duncan, J. E. Marcy, and S. F. O'Keefe. 2009 Controlling light oxidation flavor in milk by blocking riboflavin excitation wavelengths by interference. J. Food Sci. 74:S390-S398.

Webster, J. B., S. E. Duncan, J. E. Marcy, and S. F. O'Keefe. 2011. Effect of narrow wavelength bands of light on the production of volatile and aroma-active compounds in UHT milk. Int. Dairy J. $21: 305-311$

White, C. H. 1985. Consumer reaction to colored plastic milk jugs. J. Dairy Sci. 68:261-264.

Wold, J. P., A. Veberg, A. Nilsen, V. Iani, P. Jezenas, and J. Moan. 2005. The role of naturally occurring chlorophyll and porphyrins in light-induced oxidation of dairy products. A study based on fluorescence spectroscopy and sensory analysis. Int. Dairy J. 15:343-353.

Zygoura, P., T. Moyssiadi, A. Badeka, E. Kondyli, I. Savvaidis, and M. G. Kontominas. 2004. Shelf-life of whole pasteurized milk in Greece: Effect of packaging material. Food Chem. 87:1-9. 